Fecha de recepción: julio 2020

Fecha de aprobación: octubre 2020

Fecha publicación: enero 2021

\section{El libro de no ficción para prelectores. Análisis de las claves de construcción del discurso}

Marta Sampériz $^{(1)}$, Rosa Tabernero ${ }^{(2)}$, María Jesús Colón ${ }^{(3)}$ y Noemí Manrique ${ }^{(4)}$

Resumen: En el panorama editorial español actual, el libro de no ficción constituye uno de los sectores de mayor vitalidad. En el marco de estudios como los de María Bonnafé (2008) y Graciela Montes (2017) y con el fin de identificar algunas claves de construcción del discurso, este artículo propone el análisis de una selección de libros para prelectores que vinculan arte, conocimiento y juego. Así, elementos como la fisicidad, la interactividad lúdica y la elipsis vinculada al paso de página se definen como rasgos característicos de las obras elegidas. Esta investigación forma parte del Proyecto I+D+i Formar lectores en la sociedad digital desde el libro de no ficción (RTI2018-093825-B-I00).

Palabras clave: Libro de no ficción - Prelectores - Arte - Conocimiento - Fisicidad.

[Resúmenes en inglés y portugués en la página 90]

(1) Investigadora predoctoral del área de Didáctica de la Lengua y la Literatura de la Universidad de Zaragoza. Es miembro del Grupo de Investigación de referencia ECOLIJ. Sus líneas de investigación: estudios teóricos del libro de no ficción; entornos rurales.

(2) Profesora del área de Didáctica de la Lengua y la Literatura de la Universidad de Zaragoza. Es Investigadora Responsable del Grupo de Investigación de referencia ECOLIJ. Sus líneas de investigación: estudios teóricos de análisis del discurso literario infantil y juvenil; desarrollo de hábitos lectores.

(3) Profesora del área de Didáctica de la Lengua y la Literatura de la Universidad de Zaragoza. Es miembro del Grupo de Investigación de referencia ECOLIJ. Sus líneas de investigación: estudios teóricos del álbum sin palabras; contextos rurales.

(4) Profesora del área de Didáctica de la Lengua y la Literatura de la Universidad de Zaragoza. Es miembro del Grupo de Investigación de referencia ECOLIJ. Sus líneas de investigación: estudios teóricos de las actitudes de los mediadores; análisis del discurso literario infantil. 


\section{Introducción}

Estudios como los de Millán (2015) y Cordón-García (2018), entre otros, muestran los cambios que el desarrollo tecnológico ha provocado en la concepción del libro en todos sus niveles, desde el concepto de autoría, hasta su materialidad proponiendo una nueva experiencia de lectura. Así se explica la creciente incorporación de los libros de conocimientos al mercado editorial español, tanto de traducciones como de libros de producción propia, en un marco de hibridación de paradigmas digitales y analógicos. En la actualidad, el libro de no ficción forma parte de una extraordinaria expansión y se ha visto renovado, tanto en sus formas como en sus contenidos, en favor de una representación conjunta de arte y conocimiento. Si la llegada de internet supuso un oscurecimiento de los libros infantiles de conocimientos, los comienzos del siglo XXI han sorprendido a los lectores, desde la perspectiva editorial, con una publicación ingente de álbumes ilustrados de no ficción dirigidos a la infancia y a la juventud ante la necesidad de responder al desarrollo de la competencia informacional desde el ámbito educativo como uno de los grandes retos de la sociedad del conocimiento. Así la vinculación de arte y conocimiento resulta una de las características de la nueva era desde la premisa que tanto uno como otro comparten la sensación de deslumbramiento tan próxima a la curiosidad (Montes, 2017). Por otra parte, ante la inmensidad de la información, el libro propone al lector una lectura guiada a través de los límites que espacialmente sugiere el objeto libro.

Este nuevo impulso del libro de no ficción se produce también con la intención de aproximar una lectura informacional de calidad al receptor infantil y juvenil. En la sociedad actual, la información inmediata y globalizada se encuentra al alcance de cualquier lector $y$, en consecuencia, el desarrollo de la competencia informacional desde edades tempranas supone un reto al que las escuelas, los mediadores y las editoriales deben responder. La incorporación de límites y pautas que faciliten la selección y el tratamiento de la información resulta necesaria, por tanto, en los procesos de enseñanza y aprendizaje. A este respecto, los libros de no ficción pueden resultar útiles en tanto que transmiten una información limitada, fiable y organizada (Baró, 1996; Carter, 2001; Garralón, 2013; Lartitegui, 2018), una información que, en el caso de los libros para prelectores, se traslada al receptor a través de recursos lúdicos y artísticos que merecen ser observados desde el marco que se ha expuesto.

Con este objetivo, desde el marco del proyecto $\mathrm{I}+\mathrm{D}+\mathrm{I}$ «Formar lectores en la sociedad digital desde el libro de no ficción», se propone el análisis de tres álbumes: ¡A dormir gatitos!, La calle Mayor, y Niño, huevo, perro, hueso, obras dirigidas a niños de 3 a 6 años. El propósito del estudio es analizar sus elementos físicos y materiales y extraer las claves que conforman los elementos discursivos. El concepto de libro de no ficción y la fisicidad del libro enmarcan el estudio, puesto que de ellos se desprenden los aspectos que han resultado de interés en el análisis. 


\section{El libro de no ficción}

Las colecciones de libros de conocimiento publicadas en los años 90 ya pronosticaban la transformación actual de los libros de no ficción en el panorama literario infantil y juvenil (Baró, 1996). Se trataba de libros que dibujaban un tipo de lector infantil curioso y crítico que se aproximaba a los libros para saber más (Carter, 2001; Garralón, 2013). Surge así la concepción del libro de no ficción vinculada al uso de un discurso informativo, estructurado y veraz que estimula la curiosidad y el interés del lector infantil y juvenil.

Por otra parte, los estudios sobre el libro de no ficción que contemplan tanto la lectura estética como la lectura eferente (Carter, 2001) son especialmente relevantes en este momento al establecer una vinculación significativa entre arte y conocimiento (Machado, 2017; Montes, 2017). Ambos aspectos resultan fácilmente reconocibles en las nuevas propuestas editoriales y conforman un binomio inseparable en la actual construcción de sentido.

Finalmente, la utilización de componentes lúdicos y físicos ha favorecido la renovación del libro informativo: "Los libros de este tipo proponen experiencias y apelan al lector en su faceta lúdica. En esta tarea, todos los elementos de la dimensión material del libro quedarán comprometidos" (Lartitegui, 2018, p. 51). En definitiva, estos elementos contribuyen a configurar un paradigma lector en el que los conocimientos se transmiten organizados a través de los límites que propone la fisicidad del libro en un discurso lúdico que solicita continuamente la participación interactiva del receptor en la construcción de sentidos (Ramos, 2019). A este respecto conviene referirse a Un libro de Hervé Tullet (Kókinos, 2011) como uno de los puntos de inflexión en el panorama editorial en lo que a la interactividad del lector con el libro se refiere siempre con el telón de fondo de la lectura en pantalla. Tanto es así que se podría afirmar que la obra de Tullet marca una etapa de producción en el libro de no ficción para los más pequeños caracterizada por la interactuación física del lector con el libro en la construcción del discurso. El lector de Un libro debe seguir las órdenes del narrador para que el discurso evolucione.

\section{El libro como objeto}

Los estudios de Pelachaud (2010, 2016) y Trebbi (2015) sobre los libros animados -libros de artista que rompen las dos dimensiones de la página y contienen mecanismos lúdicosmuestran una larga tradición del libro objeto, tanto en publicaciones ficcionales como obras no ficcionales especialmente sofisticadas. Estos trabajos sitúan el nacimiento del libro animado infantil en el siglo XVIII y consideran a los inventores y creadores de los primeros libros tridimensionales como los precursores de la interactividad. Actualmente, esta tradición se ha nutrido además de la lectura hipertextual y contempla un nuevo lector habituado a las pantallas y a la virtualidad (Tabernero, 2017). Paradójicamente, en la última década, los pronósticos sobre la desaparición del libro impreso frente a la aparición del libro electrónico y otros soportes digitales no sólo han fracasado, sino que el diseño del objeto físico y los componentes paratextuales del libro se han visto especialmente revitalizados (Cordón-García, 2018; Tabernero, 2019). 
Asimismo, los fundamentos artísticos y lúdicos que caracterizaban el álbum son compartidos por los actuales libros de no ficción, de forma que, en esta revitalización del objeto libro a la que asistimos, la ficción y la no ficción han establecido puentes formales y discursivos en tanto que se detecta una tendencia a la disolución de los límites y a la hibridación de las propuestas.

Se observa así que la materialidad del libro construye el discurso (Tabernero, 2019) y condiciona la relación entre el libro y el lector. Como señala Littau (2006), la lectura es también una forma de expresión corporal, la relación entre dos cuerpos, una experiencia que afecta al lector porque el objeto modifica nuestra relación con la lectura. Desde esta perspectiva, resulta evidente que las nuevas propuestas editoriales dirigidas a prelectores ofrecen principalmente una forma lúdica de relación física con el libro que condiciona la experiencia de lectura. Este lector modelo (Eco, 1981) como estrategia discursiva o lector ideal que parecen proponer los libros de no ficción para prelectores necesitará ser competente y hábil en el manejo interactivo del objeto, en el disfrute lúdico, en el aprendizaje conceptual o en la adquisición de estrategias narrativas, un lector que muestre una respuesta estética (Genette, 2000), temprana, pero ya compleja, a la propuesta artística que se le ofrece.

\section{Selección del corpus}

Los criterios que han condicionado la selección del corpus de obras de no ficción para prelectores obedecen a las observaciones previamente expuestas. Aspectos como el concepto de libro de no ficción, la edad de los lectores y la presencia en el mercado editorial actual han guiado la propuesta. De este modo, se realizó una búsqueda de libros para prelectores en diferentes catálogos editoriales con cierta trayectoria en el panorama literario infantil español. Finalmente, se consideró que las publicaciones de los últimos años podían ser más significativas por aportar una proximidad evidente a la edición actual del libro de no ficción para prelectores. Así las tres obras escogidas han sido publicadas en los últimos cinco años por editoriales españolas que han cuidado especialmente las propuestas de no ficción dirigidas a la infancia y la vinculación entre el soporte y el conocimiento en la construcción de sentidos ha sido el criterio que ha inspirado la selección en última instancia. Se ha primado, en este sentido, la concepción de proyectos editoriales más allá de la singularidad de la obra. Por esta razón, los títulos seleccionados pertenecen a editoriales especializadas en el libro de no ficción para niños, como es el caso de Zahorí Books o Wonder Ponder o a editoriales especializadas en álbum ilustrado de ficción y no ficción para las primeras edades, tal como ocurre con Timunmas.

En este marco, los títulos escogidos han sido: ¡A dormir gatitos! (2018) de editorial Zahorí Books, La calle Mayor (2019) de editorial Timunmas y Niño huevo perro hueso (2019) de Editorial Wonder Ponder.

¡A dormir, gatitos! (Figura 1) fue publicado en 2018 en Barcelona (España) por la Editorial Zahorí Books, editorial especializada en libro ilustrado de no ficción. Con esta obra, la autora e ilustradora Bàrbara Castro Urío inicia la colección "Buenas noches" que se 


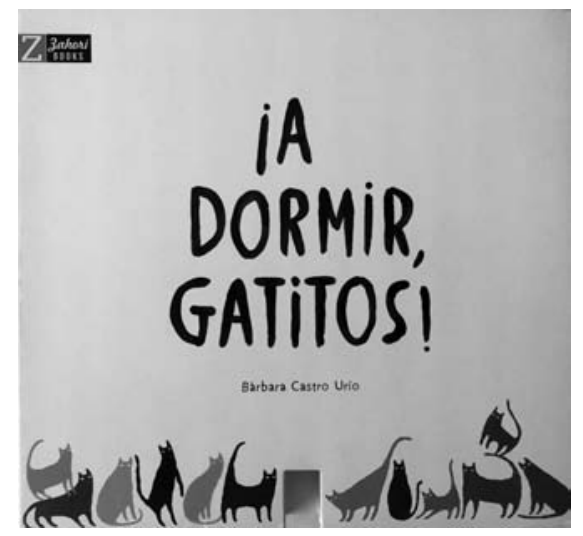

Figura 1. Cubierta de ¡A dormir gatitos! Fotografía propia.

completa, hasta el momento, con los títulos jA dormir, pequeña ballena! (2019) y Good Nigth Polar Bear (2018). Se trata de libros destinados a prelectores de formato cuadrado, cantos redondeados y páginas troqueladas de cartón blanco. Cada historia está protagonizada por un animal, o varios de la misma especie, que realizan actos cotidianos cercanos a las experiencias de los niños, una aproximación respetuosa con el entorno natural en sintonía con la línea editorial de Zahorí Books. En ¡A dormir gatitos! el lector podrá seguir la historia de doce gatos de diferentes colores que aparecen en la página de la izquierda para ir ocupando las habitaciones de la casa de la derecha. En este sentido, su línea argumental recuerda el álbum sin palabras Diez niños se cambian de casa de Mitsumasa Anno, publicado por primera vez en 1981 en Japón. La obra de Castro podría considerarse como una versión simplificada y renovada del libro de Anno, puesto que ambos comparten las claves de una esencia ficcional y un desafío no ficcional muy similares. De esta manera, $i A$ dormir gatitos! propone al lector el descubrimiento conceptual de los colores, los números y las formas mientras se sumerge en una historia ficcional afable y sugerente. La obra fue galardonada en la Feria Internacional del Libro Infantil de Bolonia de 2019 en la categoría “Toodler”. El jurado destacó su diseño, sobrio y minimalista, una narrativa estimulante del pensamiento afectivo lógico y analógico y el libro objeto como hogar, un lugar hospitalario que salvaguarda las características del individuo.

La calle Mayor (Figura 2) es un libro acordeón escrito por Jonathan Emmett, ilustrado por Angela P. Arrhenius y publicado en 2018 en Barcelona (España) por la editorial Timunmas (Timun Mas Infantil). La editorial está especializada en la publicación de libros para lectores infantiles y juveniles de edades comprendidas entre los 2 y los 12 años. El título original de la obra es Busy Busy Street y la adaptación al castellano ha sido realizada por Mariona Barrera. En esta obra, el lector se incorpora a la vida de una calle ficticia, denominada $\mathrm{La}$ calle Mayor, calle en la que varios animales aparecen desarrollando su día a día en los lugares más emblemáticos. Una vez que el lector abre el libro acordeón, conoce a un vecindario particular donde sus "ciudadanos animales" están realizando diferentes acciones. Los 


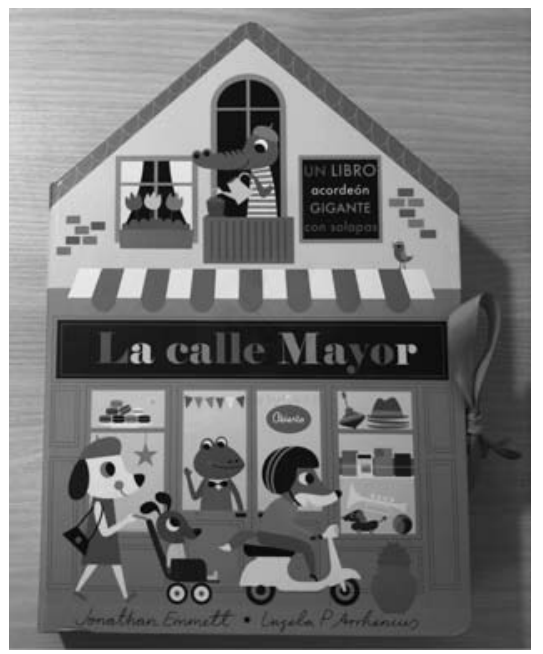

Figura 2. Cubierta de La calle Mayor. Fotografía propia.

personajes se pasean por una pastelería, una cafetería, una tienda de ropa, una lavandería, un quiosco y por otros lugares de la calle. En la parte exterior del libro acordeón, hay un camino que guía el recorrido visual del lector a través de los pliegues y que le descubre el paseo de todos los animales por el parque. En el borde derecho de la cubierta, la casa se cierra y se abre con un lazo azul que permite la "entrada" y "salida" del lector en el juego de búsqueda, de lectura y de observación. En el interior del libro acordeón, cada uno de los pliegues tiene un título que da nombre al lugar de la calle y dos solapas, una en la parte superior y otra en la parte inferior, que desvelan lo que está ocurriendo en cada ventana. En la parte interior de las solapas aparece un texto que describe la acción y el nombre de los personajes mientras que en la ventana interior se esconde una imagen detallada de las diferentes acciones. La función de los animales protagonistas es la de presentar, a través de los códigos gráfico y textual, a los distintos ciudadanos, sus lugares y oficios, en una calle mayor ficticia que conecta con las experiencias que puede tener el lector en su vida real.

Niño huevo perro hueso (Figura 3) fue publicado en 2019 por Wonder Ponder, editorial especializada en filosofía visual para niños. Wonder Ponder es un sello de Traje de Lobo S.L. con sede en Madrid (España). Este proyecto lo llevan a cabo Ellen Duthie (texto), Daniela Martagón (ilustración) y Raquel Martínez (editora). Se trata de un libro para prelectores cuya propuesta llegó al mercado editorial de la mano de otro libro que lleva por título Niña gato agua pato, ambos relacionados con las áreas o ámbitos de conocimiento del primer ciclo de la educación infantil y, por tanto, con las necesidades e intereses de los niños de 0 a 3 años. "Mirar, leer y pensar" es el lema de la editorial Wonder Ponder que dispone en su catálogo de una colección de libros en un formato de caja. Dichas cajas están abiertas a la exploración gracias a la flexibilidad en el diseño y en sus propuestas de uso. Wonder Ponder publica estos dos títulos para prelectores partiendo del mismo 
método experimental, sistemático y no directivo que pretende estimular la creatividad y el pensamiento filosófico. Esta obra es un "libro para pararse a mirar", tal y como lo define la propia editorial. Los aspectos materiales del libro proponen esta exploración gracias a su formato cuadrado con esquinas redondeadas, formato favorable para este tipo de lectores debido al momento evolutivo, sensorial y motriz en el que se encuentran. La obra discurre a través de la sucesión de dobles páginas en las que los cuatro protagonistas de la acción un niño, un perro, un huevo y un hueso- adquieren distintas disposiciones en cada escena provocando situaciones surrealistas en el más puro estilo del nonsense.

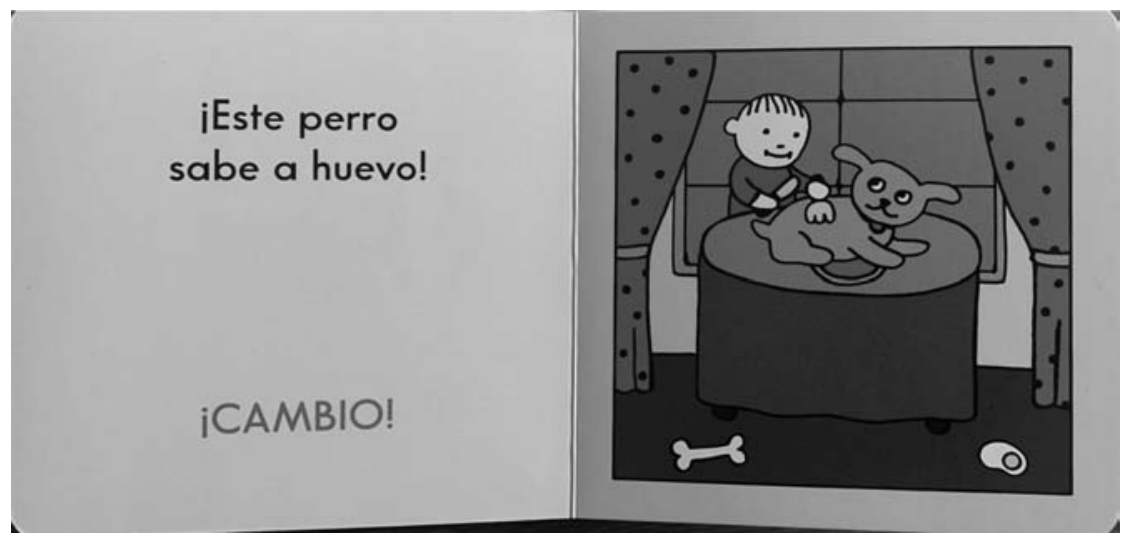

Figura 3. Doble página de Niño huevo perro hueso. Fotografía propia.

Comienza el libro con una estructura espacial que se repetirá en todo momento: página izquierda con una enumeración textual de los cuatro elementos que va generando distintas combinaciones y con un mismo pie de página en mayúsculas rojas-iCAMBIO!-con el que se ordena al lector que vuelva la página para asistir a otra disposición de los elementos. En la página de la derecha, siempre enmarcada por las cortinas de un telón teatral, los cuatro elementos aparecen en la disposición que indica el texto correspondiente. Poco a poco las funciones iniciales de cada uno de los elementos se irán intercambiando hasta terminar en situaciones inverosímiles: "Niño. ¡Perro al plato! Hueso, huevo. ¡CAMBIO!”

Se trata de un libro para prelectores que requiere un tipo de lectura en compañía donde el mediador dinamice la observación. Dentro de la categoría de "libros para pensar" sobre filosofía y pensamiento, en Niño huevo perro hueso no sólo la ilustración plantea el reto de construir nuevos significados, el texto, a través de preguntas directas incita a la curiosidad y al pensamiento. Por otra parte, tal como mencionan los estudios recientes (Lluch, Tabernero y Calvo, 2015; Cordón-García, 2018; Cordón et al., 2019), en la línea de la modificación del ecosistema del libro aparecen epitextos virtuales -textos generados por el texto- de carácter lúdico como los que corresponden a los juegos que genera esta obra (Wonder Ponder, 2019). 


\section{Las claves de construcción del discurso}

Tras la presentación de las obras seleccionadas y después del análisis detallado de cada una de ellas, dos son las claves más destacadas de construcción que comparten: la fisicidad que implica la interacción lúdica y la elipsis ficcional vinculada al paso de página. Estas claves pueden constituir asimismo rasgos definitorios de las obras de no ficción destinadas a los prelectores en los últimos años.

\subsection{La fisicidad. La materialidad del libro en la interacción lúdica}

¡A dormir, gatitos! retoma aspectos físicos característicos de los libros para bebés como el formato cuadrado, la página de cartón o los troquelados. La materialidad de sus obras activa la exploración visual y táctil, el aprendizaje y el juego como primeras formas de acercamiento al libro en la idea de que los niños "leen con las manos" y la manipulación implica una aprehensión de contenidos, tal como señalaba María Bonnafé (2008). Al mismo tiempo, su diseño minimalista, la abstracción de las figuras o el dominio del blanco aportan un estilo cuidado y diáfano al objeto libro, una propuesta artística que recuerda a autores clásicos como Bruno Munari, Leo Lionni o Iela Mari. En el espacio de jA dormir gatitos!, por ejemplo, la ocupación mínima de los personajes permite que el blanco se extienda en la doble página de forma que el foco de atención se traslada a las sutiles variaciones entre páginas, como las ventanas troqueladas que se irán iluminando mientras llega la noche. Castro también simplifica al máximo la figura de la casa (Figura 4), tan solo un trazo gris perfila una silueta que representa el hogar más tradicional y reconocible desde la infancia, un marco de página que resguarda a los gatos y al pequeño lector cuando se disponen a dormir.

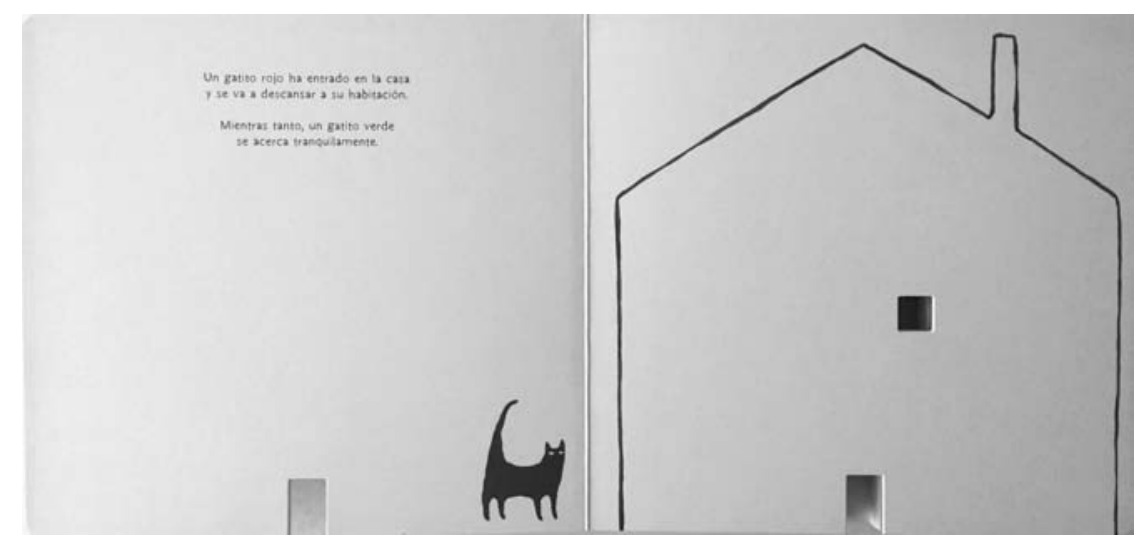

Figura 4. Primera doble página de $i A$ dormir gatitos! Fotografía propia. 
Esta abstracción de la casa, reiterada en las páginas de la derecha, contribuye a considerar el libro en tres dimensiones como una casa de muñecas con puertas y ventanas troqueladas que incitan a ser traspasadas con la mirada y con las manos. Podría decirse que el soporte de ¡A dormir gatitos! es un objeto lúdico y artístico compuesto por un abanico de catorce paneles dispuestos sobre un eje, un libro-casa con doce gatos de colores que lo habitan, que se asoman y se esconden, un libro que interpela a la curiosidad del lector, que estimula sus sentidos y lo invita cada noche a actuar en este escenario para jugar al escondite con sus inquilinos y adentrase con ellos en el momento del sueño. Página a página, el narrador induce a la ruptura de la cuarta pared (Tabernero, 2017) y hace partícipe al lector en la construcción del guión a través de un discurso apelativo e incompleto. La experiencia de lectura se convierte así en una dramatización que será representada cada noche y el espacio de la doble página será el escenario metaficcional que permitirá a los niños apropiarse del libro y acceder -mediante la interacción lúdica, el descubrimiento cognitivo y la vertebración ficcional de la historia- a su valor simbólico (Thollon-Behar e Ignacchiti, 2019).

En La calle mayor, la interacción lúdica que exige la dimensión objetual del libro involucra al lector infantil durante su aprendizaje. Los conceptos físicos y materiales adquieren relevancia por el formato artístico, el diseño gráfico y la lectura de solapas que componen la obra de Emmett y Arrhenius. El formato cartoné de canto redondeado responde a la normativa de edición que se exige en los libros para niños muy pequeños que son todavía prelectores (Squilloni, 2019).

Los aspectos materiales -que componen el diseño del libro acordeón-proponen el juego de búsqueda, de observación y de conocimiento. Las editoriales infantiles valoran en este tipo de propuestas no solo las implicaciones lúdicas sino también las implicaciones narrativas y estéticas que la obra posibilita (Ramos, 2019). La composición teatral del libro (Tabernero, 2019b) se representa desde la cubierta en La calle Mayor. De manera ordenada se muestra una casa que simula un teatro de guiñol con unos personajes que irán conformando artísticamente cada una de las páginas desplegadas del libro. La perspectiva teatral se refleja en los planos fijos, en la concepción de las dobles páginas como espacios escénicos en los que los personajes se desplazan (Tabernero, 2019b). De la misma manera, el formato cartoné del libro acordeón con sus pliegues y solapas (Figura 5) constituye uno de los elementos visuales que son clave en la construcción del discurso. La lectura del libro por la parte interior del acordeón se puede realizar con la doble página abierta, con el paso de página o de manera fragmentada (Reis y Roig, 2019).

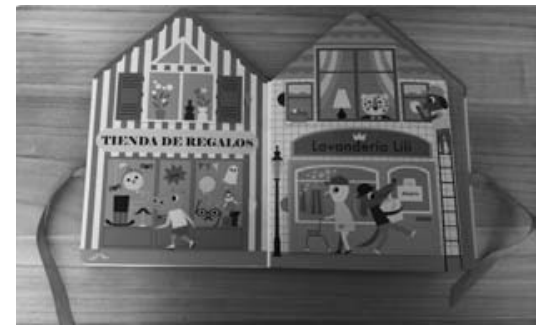

Figura 5. Doble página

de La calle Mayor.

Fotografía propia. 
Sin embargo, cuando se toma la parte exterior del libro, los pliegues y el movimiento secuencial obligan al lector a salir y ver cómo todos los personajes están jugando en el parque. Se produce de este modo un juego entre los espacios exteriores (Figura 6) e interiores del libro por los que el lector transitará acompañando a los personajes. La ruptura de niveles de ficción a modo de metalepsis (Genette, 2000; Tabernero, 2019a) es provocada por la irrupción necesaria del lector en el espacio del libro.

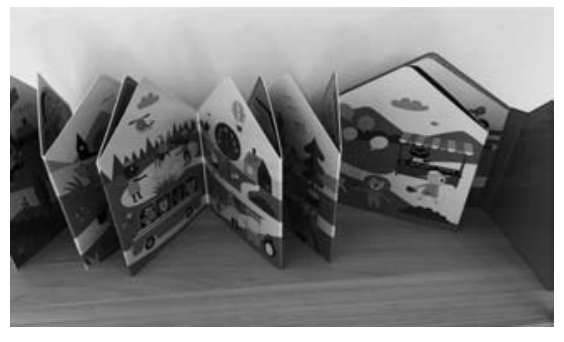

Figura 6. Pliegues

externos de La calle

Mayor. Fotografía propia.

Asimismo, en Niño huevo perro hueso, se destaca el componente de teatralidad donde el lector parece convertirse en espectador puesto que se produce la ruptura de la cuarta pared que caracteriza al género (Tabernero, 2017). Niño huevo perro hueso se presenta como una obra de teatro, un escenario donde los personajes van cambiando de posición y obligan al lector/espectador interactivo a colaborar en la construcción del discurso en cada paso de página. Desde que el lector abre la cubierta (Figura 7) y vuelve la página hablamos de una interacción con la materialidad del objeto para llevar a cabo el acto de leer (Tabernero, 2019c). Así, las páginas de Niño huevo perro hueso tienen un fondo de color amarillo en cuyo lado izquierdo se encuentra el texto, desempeñando la función básica de anclaje para anular la polisemia de la imagen, y en el lado derecho se exponen las ilustraciones donde se desarrollan las escenas. En esta disposición espacial, entendida como eje del discurso, las ilustraciones de la página derecha actúan como generadores de sentido mediante planos fijos que se encuentran enmarcadas por cortinas teatrales.
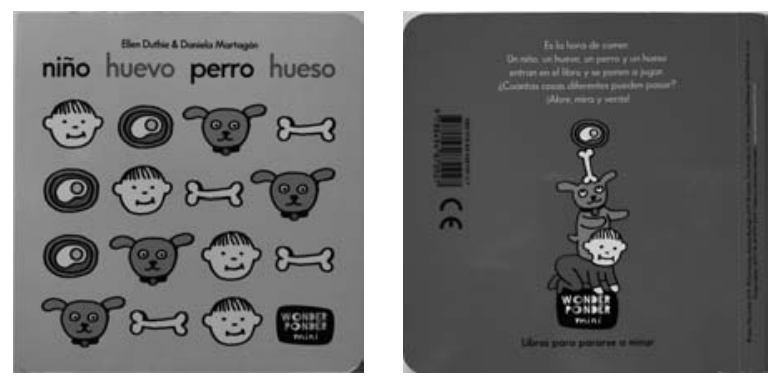

Figura 7. Cubierta y contracubierta de Niño huevo perro hueso. Fotografía propia. 
El concepto de escena ya se presenta desde la cubierta, donde se muestra a los personajes en diferentes posiciones, pero manteniendo una estructura ordenada y secuenciada que transmite sensación de quietud. Sin embargo, en la contracubierta (Figura 7) aparecen los mismos personajes en acción realizando divertidos movimientos y equilibrios, la fisicidad del libro dirige al lector a una lectura hipertextual (Tabernero, 2019a).

En la primera doble página, el lector se encuentra ante un escenario donde los personajes están representando una situación real, lógica y verosímil (el niño come un huevo en la mesa y el perro come un hueso en el suelo) y el texto así lo describe. Sin embargo, el texto, en letra minúscula y de color negro, avisa al lector de que algo va a suceder, dando comienzo la función, no solo por lo que dice el texto sino por cómo lo dice, ya que la tipografía del texto es diferente porque la palabra "cambio" está en mayúsculas y es de color rojo ("Niño, huevo, perro, hueso. ¡CAMBIO!”). Desde el análisis de la relación entre el texto y la ilustración, se observa cómo la ilustración amplía lo que dice el texto, es decir, se corresponde con la categoría de ampliación que define Sophie Van der Linden (2015). El narrador textual invita al lector a combinar cuatro elementos que son pares naturales (niño-huevo / perro-hueso) rompiendo la lógica en las sucesivas escenas surrealistas. Así, el lector debe fijar la atención en las ilustraciones y reparar en el cambio que se produce. Esta relación entre texto e imagen, y la interacción con la materialidad del libro como estrategia discursiva definen el acto de leer en esas primeras edades. Por tanto, este lector infantil construye significado al responder a las preguntas que plantea el libro, juega y se apropia del lenguaje a través de un tipo de descubrimiento que produce satisfacción.

\subsection{Elipsis ficcional en el paso de página}

La elipsis que se crea con el paso de página en ¡A dormir gatitos! supone el avance cronológico de una trama narrativa de carácter ficcional que comporta al mismo tiempo una propuesta no ficcional de estimulación sensorial y cognitiva para los lectores infantiles. La narración es acumulativa. Con cada paso de página, entra en escena un gato quien, próximo a la casa, espera su turno para colarse por la puerta troquelada, una ranura que recuerda las tradicionales gateras (Figura 8). De esta forma, uno a uno, doce gatitos irán apareciendo en la página de la izquierda en una posición fija, ubicación que podría sugerir que se trata siempre del mismo gatito - un único personaje que cambia de color, tal y como sucede en el segundo título de la serie, ¡A dormir, pequeña ballena!, . Sin embargo, cada paso de página supone una elipsis, un vacío narrativo que el lector deberá restituir. Cuando el pequeño lector pase de página, habrá pasado también el tiempo, el lapso que permita al gato entrar por la gatera y ocupar una habitación de la casa para que otro felino pueda colocarse en su lugar. Un tiempo y una acción que son omitidos en las imágenes, pero que se referencian en un breve texto que ejerce de anclaje (Barthes, 1964) y facilita la interpretación narrativa. 


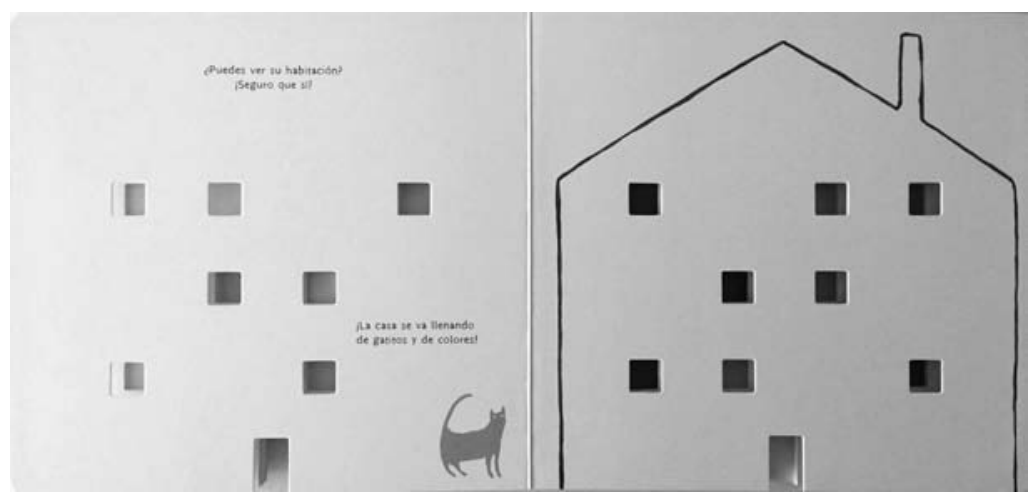

Figura 8. Doble página de $i A$ dormir gatitos! Fotografía propia.

En las primeras páginas, el texto descubre la elipsis visual, un comienzo fundamental para internarse en el juego reiterativo que se propone al lector. Después, el discurso adquiere un carácter apelativo. El narrador introduce preguntas y expresiones de sorpresa que interpelan al lector para que mire con atención la escena, se interrogue sobre las ausencias, busque, observe los cambios e imagine lo sucedido. La aparición ordenada de las ventanas troqueladas en la casa de la derecha refuerza además la secuenciación y la construcción tanto de una línea narrativa como de un juego numérico que no viene asociado al reconocimiento gráfico, sino a la estimulación del cálculo mental incentivado por la mediación del adulto. Desde esta propuesta ficcional, fragmentada por la elipsis en cada paso de página, el lector podrá aproximarse al descubrimiento de las formas, los colores y el conteo (Figura 9), un reto no ficcional que funciona en este libro como un juego de pistas que le permitirán reconstruir los vacíos de información e imaginar los acontecimientos narrativos omitidos en las imágenes.

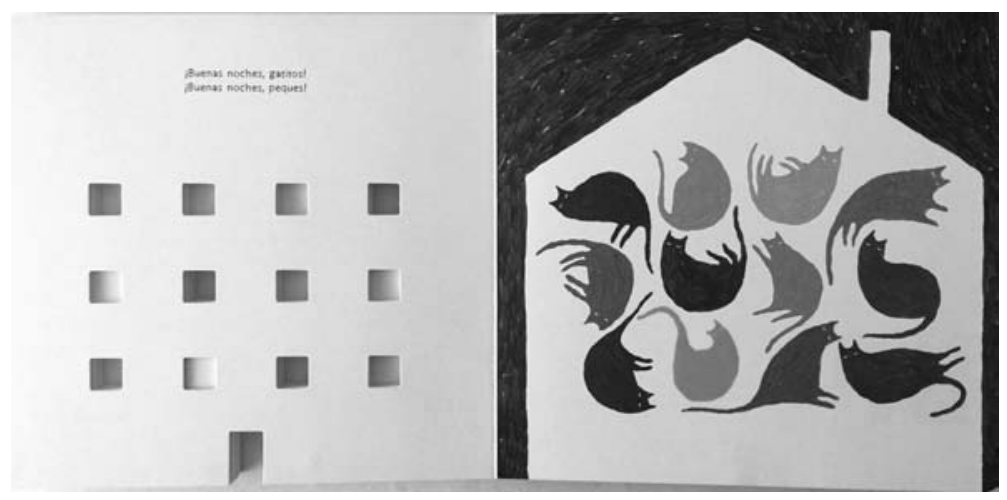

Figura 9. Doble página final de ;A dormir gatitos! Fotografía propia. 
En la obra La calle Mayor, la elipsis ficcional vinculada al paso de página forma parte del componente lúdico de búsqueda, juego y observación a través de los pliegues (Figura 10) y las solapas. El juego de descubrimiento crea una elipsis temporal vinculada al paso de página y al movimiento de pliegues y solapas en el libro acordeón.

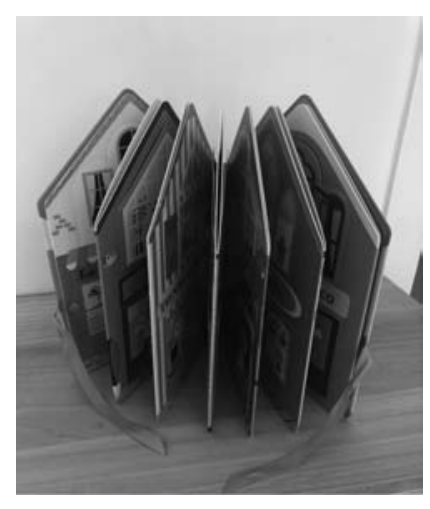

Figura 10: Pliegues

interiores de La calle

Mayor. Fotografía propia.

Claves como los espacios interactivos del libro que permiten adentrarse en el pliegue (Tabernero, 2017) -para descubrir el texto y las imágenes ocultas detrás de las solapas (Tabernero, 2019a)- junto con el movimiento del paso de página componen la materialidad y especificidad de esta obra. La elipsis ficcional que esconde la secuencia narrativa de la obra se descubre con el paso de página, el movimiento de los pliegues y el levantamiento de las solapas (Figura 11). Desde el movimiento de los pliegues hasta el descubrimiento de las solapas se produce una elipsis temporal y visual en la que el lector interactúa con el libro y -en este espacio fragmentado de tiempo- se despierta la curiosidad y la atención del prelector por averiguar lo que se esconde detrás de cada paso de pliegues y de solapas.

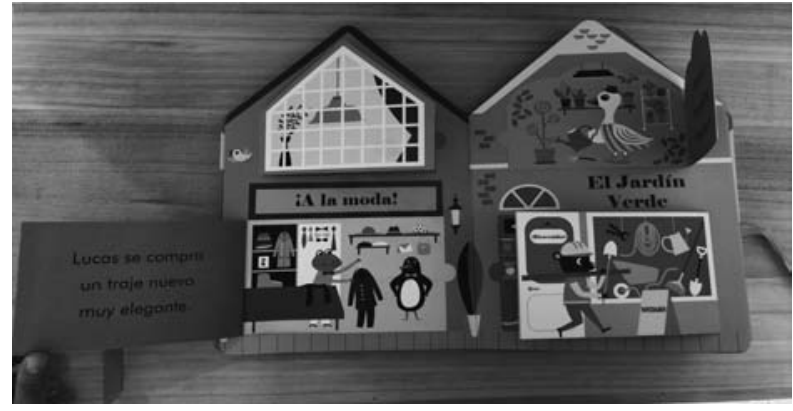

Figura 11: Doble página de La calle Mayor. Fotografía propia. 
El lector se siente involucrado de manera activa en cómo manipular y explorar el libro (Ramos, 2019). Así la información llega al lector a través de la narración ficcional que los personajes van protagonizando. En La calle Mayor, ficción y no ficción conforman un binomio inseparable en la construcción de los aprendizajes y conocimientos que se aproximan al lector. Con esta propuesta ficcional -secuenciada y fragmentada narrativamente con el paso y el movimiento de los pliegues internos y externos- el lector podrá aproximarse a conceptos como las profesiones, los oficios, las tiendas y las calles que aparecen en el libro de no ficción.

En el caso de Niño huevo perro hueso, cuando el lector pasa la página los personajes continúan en la misma posición, pero dos elementos han cambiado, el niño tiene en la mesa un hueso y el perro se dispone a comer un huevo, este juego de disparates rompe la lógica y dota de presencia a una historia ficcional, de tal modo que algo ha ocurrido en ese espacio elíptico marcado por la vuelta de página (Figura 12). Los cuatro elementos (niño-huevo / perro-hueso), durante todo el relato, comparten el mismo escenario y van cambiando de posición dando paso a una realidad ficcional que se desarrolla en el espacio que el lector intuye, pero no ve (Tabernero, 2019a). Así, tanto en el séptimo como en el octavo paso de página, el texto y las ilustraciones exponen una realidad ficcional donde el niño aparece representado comiendo un perro y preguntándose si sabe a huevo, y en el octavo salto de página se observa al perro lamiendo al niño como si supiera a hueso. El lector tiene la sensación de que el estatismo que se produce en cada doble página viene creado por el movimiento de los cuatro protagonistas en los espacios del paso de página, espacios en los que se desarrollan elementos ficcionales desconocidos.

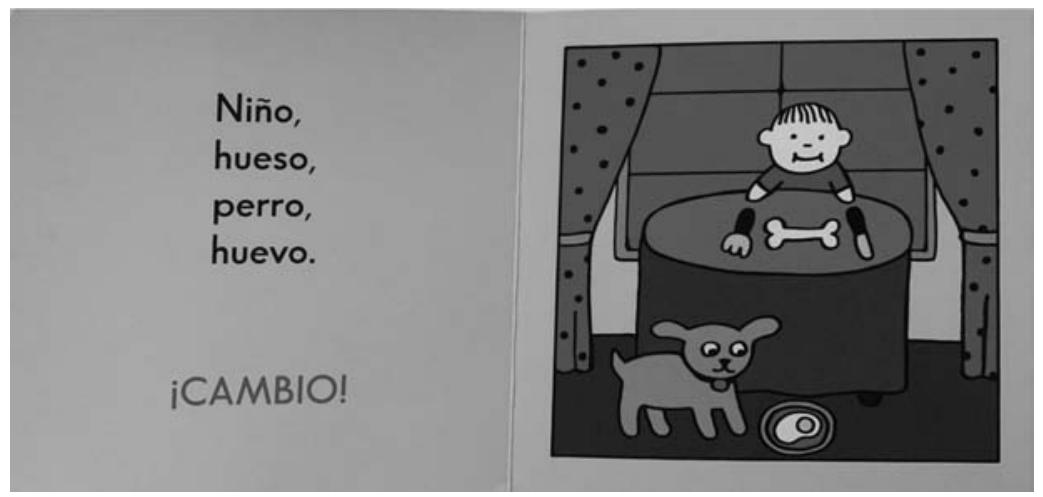

Figura 12: Doble página de Niño huevo perro hueso. Fotografía propia. 


\section{Conclusiones}

El análisis de las tres obras seleccionadas ha mostrado algunas de las claves que definen en estos momentos el discurso de los libros de no ficción dirigidos a prelectores. Así la potenciación de la fisicidad del libro como objeto y la interactividad lúdica en el proceso de lectura junto a la elipsis ficcional que se produce en la vuelta de página son características definitorias del discurso estudiado.

El paso de página se ha convertido en un recurso ficcional que se utiliza también en el libro de no ficción en la aproximación de los prelectores a la lectura. La búsqueda lectora genera que, a través del movimiento de los pliegues, el conteo de gatos y el juego de lógica, se estén activando procesos que interpelan activamente al lector en la construcción del discurso narrativo. Estas propuestas responden a la renovación del libro infantil que recupera la propuesta iniciada por los Prelibri de Munari, en el juego con los aspectos matéricos del libro en la construcción de sentidos (Jiménez, 2019).

El juego resulta ser un elemento simbólico presente en el análisis de las tres obras escogidas para expresar, a través del libro de no ficción, un conocimiento o una experiencia significativa en la vida del prelector. Elementos como el juego, la búsqueda y la observación definen la mayor parte de la obra La calle Mayor entre los pliegues y las solapas de este libro acordeón. Por otra parte, los troquelados de las ventanas de la casa en jA dormir gatitos! aproximan al lector una interacción lúdica propia de la ficcionalidad en la que la propuesta artística del libro le interpela de manera activa en los espacios sugeridos por el paso de página. Del mismo modo, el juego del lenguaje (Rodari, 2002) además de la historia intuida en los huecos creados por la vuelta de página en el libro Niño huevo perro hueso aporta un aspecto ficcional a las experiencias reales de los lectores. En definitiva, los tres libros de no ficción presentan una propuesta para prelectores desde la materialidad (Littau, 2006) en la construcción del discurso del libro objeto. Los personajes guían el relato de búsqueda (Tabernero, 2019a) en la no ficción enseñando, a través de la ficción, aprendizajes reales en la vida diaria del prelector. Los recursos ficcionales como la fisicidad del libro como objeto y la interactividad lúdica a través del juego forman parte del conjunto de claves que definen la producción editorial actual. Esta renovación del libro de no ficción, que recupera el binomio arte y conocimiento, está ocupando gran parte del catálogo editorial actual del libro de no ficción para prelectores. Se diseñan y se crean libros para un lector modelo (Eco, 1981) que se aproxima a estos libros de manera específica, por el placer de la lectura tanto estética como eferente (Baró, 1996).

\section{Referencias bibliográficas}

Anno, M. (1991). Diez niños se cambian de casa. Barcelona: Juventud.

Baró, M. (1996). Libros de conocimiento evolucionar o morir. CLIJ: Cuadernos de literatura infantily juvenil, 9(83), 7-19. Recuperado de http://www.cervantesvirtual.com/portales/ cuadernos_literatura_infantil_juvenil/obra/clij-cuadernos-de-literatura-infantil-yjuvenil-77/ 
Barthes, R. (1964). Rhétorique de l'image. Communications, 4(1), 40-51. doi: https://doi. org/10.3406/comm.1964.1027

Bonnafé, M. (2008). Los libros, eso es bueno para los bebés. Barcelona: Océano Travesía.

Carter, B. (2001). Libros de información. Del placer de saber al placer de leer. Venezuela: Banco del libro.

Castro, B. (2018). A dormir gatitos!. Barcelona: Zahorí Books.

Castro, B. (2018). Good Nigth Polar Bear. Barcelona: Zahorí Books.

Castro, B. (2019). ¡A dormir, pequeña ballena!. Barcelona: Zahorí Books.

Cordón-García, J. A. (2018). Combates por el libro: inconclusa dialéctica del modelo digital. Profesional de la Información, 27(3), 467-481. doi: https://doi.org/10.3145/epi.2018.may.02

Cordón, J. A., y Gómez, R. (Coords.). (2019). Lectura, sociedad y redes. Colaboración, visibilidad y recomendación en el ecosistema del libro. Madrid: Marcial Pons.

Duthie, E. y Martagón, D. (2019). Niña, gato, agua, pato. Madrid: Wonder Ponder.

Duthie, E. y Martagón, D. (2019). Niño, huevo, perro, hueso. Madrid: Wonder Ponder.

Eco, U. (1981). Lector in fabula. La cooperación interpretativa en el texto narrativo. Barcelona: Lumen.

Emmett, J. y Arrhenius, I. P. (2018). La calle Mayor. Barcelona: Timun Mas Infantil.

Garralón, A. (2013). Leer y saber: los libros informativos para niños. Madrid: Tarambana libros. Genette, G. (2000). La obra del arte II. La relación estética. Barcelona: Lumen.

Jiménez, J. L. (2019). Bruno Munari (1907-1998). En R. Tabernero (Ed.), El objeto libro en el universo infantil. La materialidad en la construcción del discurso (pp. 17-24). Zaragoza: Prensas de la Universidad de Zaragoza.

Lartitegui, A. (2018). Alfabeto del libro de conocimiento. Paradigmas de una nueva era. Zaragoza: Pantalia Publicaciones.

Littau, K. (2006). Teorías de la lectura. Libros, cuerpos y bibliomanía. Buenos Aires: Manantial.

Lluch, G.; Tabernero, R. y Calvo, V. (2015). Epitextos virtuales públicos como herramientas para la difusión del libro. El profesional de la información, 24(6), 797-804. doi: https:// doi.org/10.3145/epi.2015.nov.11

Machado, A. M. (2017). Punto de fuga. Bogotá: Babel.

Millán, J. A. (2015). Edición y difusión del libro. El profesional de la información, 24(6), 699-703. doi: http://dx.doi.org/10.3145/epi.2015.nov.01

Montes, G. (2017). Buscar indicios construir sentido. Bogotá: Babel.

Pelachaud, G. (2010). Livres animés. Du papier au numérique. París: L'Harmattan.

Pelachaud, G. (2016). Livres animés. Entre papier et écran. París: Pyramyd.

Ramos, A. M. (2019). Desplegar lecturas: panorama de la edición de libros-acordeón en Portugal. En R. Tabernero (Ed.), El objeto libro en el universo infantil. La materialidad en la construcción del discurso (pp. 27-44). Zaragoza: Prensas de la Universidad de Zaragoza.

Reis, S. y Roig, B. A. (2019). O Capuchinho Vermelho e os seus múltiplos papéis: para uma leitura de alguns livros-objecto. In I. Mociño, (Coord.). Libro-Obxecto e Xénero. Estudos ao redor do libro infantil como artefacto (pp. 81- 103). Vigo, España: Universidad de Vigo.

Rodari, G. (2002). Gramática de la fantasía. Barcelona: Del Bronce.

Squilloni, A. (2019). En la oficina del editor. Apuntes, técnicas y reflexiones. Zaragoza: Pantalia Publicaciones. 
Tabernero, R. (2017). El lector en el espacio libro. Fuera [de] margen. Observatorio del álbum $y$ de las literaturas gráficas, 19, 22-25.

Tabernero, R. (2019a). Descubriendo lo oculto: el espacio del lector en los libros de solapas. En R. Tabernero (Ed.), El objeto libro en el universo infantil. La materialidad en la construcción del discurso (pp. 73-85). Zaragoza: Prensas de la Universidad de Zaragoza.

Tabernero, R. (2019b). Suzy Lee y el libro como espacio de representación. En I. Mociño, (Coord.). Libro-Obxecto e Xénero. Estudos ao redor do libro infantil como artefacto (pp. 33- 50). Vigo, España: Universidad de Vigo.

Tabernero, R. (Ed.). (2019c). El objeto libro en el universo infantil. La materialidad e $n$ la construcción del discurso. Zaragoza: Prensas de la Universidad de Zaragoza.

Thollon-Behar, M. e Ignacchiti, S. (2019). De l'objet à l'histoire, le livre dans le développement de l'enfant. Enfances \& Psy, 82(2), 39-48. doi: https://doi.org/10.3917/ep.082.0039

Trebbi, J. Ch. (2015). El arte del pop-up. El universo mágico de los libros tridimensionales. Barcelona: Promopress.

Tullet, H. (2011). Un libro. Madrid: Kókinos.

Van der Linden, S. (2015). Álbum [es]. Barcelona: Ekaré.

Wonder Ponder. (25 octubre, 2019). Jugar leer con los elementos de Wonder Ponder Mini [Archivo de vídeo]. Recuperado de https://www.youtube.com/watch?v=TKWve0GEXqc

\begin{abstract}
In the current Spanish publishing scene, the non-fiction book is one of the most vital sectors. In the framework of studies such as those of María Bonnafé (2008) and Graciela Montes (2017) and in order to identify some keys to the construction of the discourse, this article proposes the analysis of a selection of books for pre-readers that link art, knowledge and game. Thus, elements such as physicality, playful interactivity and ellipsis linked to the page turn are defined as characteristic features of the chosen works. This research is part of the $\mathrm{R}+\mathrm{D}+\mathrm{i}$ Project Training readers in the digital society from the non-fiction book (RTI2018-093825-B-I00).
\end{abstract}

Keywords: Non-fiction book - Pre-readers - Art - Knowledge. Physicality.

Resumo: Na atual cena editorial espanhola, o livro de não ficção é um dos setores mais vitais. No marco de estudos como os de María Bonnafé (2008) e Graciela Montes (2017) e com o objetivo de identificar algumas chaves para a construção do discurso, este artigo propõe a análise de uma seleção de livros para pré-leitores que vinculam arte, conhecimento e jogo. Assim, elementos como fisicalidade, interatividade lúdica e reticências vinculadas à virada da página são definidos como características das obras escolhidas. Esta pesquisa faz parte do Projeto $\mathrm{P}+\mathrm{D}+\mathrm{i}$ Treine leitores na sociedade digital a partir do livro de não fiç̧ão (RTI2018-093825-B-I00). 
Palavras chave: livro de não-ficção - preletores - arte - conhecimento e fisicalidade.

[Las traducciones de los abstracts fueron supervisadas por el autor de cada artículo] 